\title{
Intra-Spinal Cord Lipoma without Spinal Dysraphism
}

\author{
Dr. Roshni A*, Dr. Sudhir Saxena, Dr. Saurya, Dr. Anurag Modi
}

Department of Radiagnosis and Imaging, All India Institute of Medical Sciences, Rishikesh, Uttarakhand, India

*Corresponding author: Dr. Roshni A

Abstract

Intraspinal cord lipoma is an uncommon benign tumour with an incidence of $<1 \%$ of all spinal cord tumors. It is commonly associated with spinal dysraphism. However, lipoma without spinal canal abnormalities is rare with only a few case reports in the literature. Here, we report a case of intraspinal cord lipoma without spinal dysraphism in a 17year-old male patient with progressive numbness and spastic paraplegia. Multiplanar MRI revealed a large lipoma in the dorsal spinal cord. The patient underwent surgery and was confirmed histopathologically.

Keywords: Lipoma, Intramedullary, without dysraphism.

Copyright @ 2020: This is an open-access article distributed under the terms of the Creative Commons Attribution license which permits unrestricted use, distribution, and reproduction in any medium for non-commercial use (NonCommercial, or CC-BY-NC) provided the original author and source are credited.

\section{INTRODUCTION}

Spinal cord lipomas can be extradural, intradural and intramedullary. Intraspinal cord/ intramedullary lipoma is an uncommon entity that constitutes $<1 \%$ of all spinal cord lesions [1]. It is commonly seen in young people in their second or third decades of life. No sex predilection is seen. It is commonly seen in the upper thoracic and cervical regions [2]. The clinical course in these cases is usually slow and progressive. Multiplanar MRI is the investigation of choice and can be diagnostic also. This case report reviewed the diagnosis, imaging and treatment of a patient of intraspinal cord lipoma.

\section{Case Report}

A 17-year-old male presented to our neurology clinics with complaints of progressive decreased sensation and weakness of bilateral lower limbs for the last 2 years. The patient's birth history was normal. The skin over the spine was intact without any defect. On examination, no congenital deformity was seen. Neurological examination revealed spastic paraparesis with brisk reflexes and decreased tone in both lower limbs. The lower limbs had decreased proprioception. No bowel and bladder involvement was seen.

The patient underwent a multiplanar MRI of the dorso-lumbar spine and revealed a well-defined oblong intramedullary spinal cord lesion extending from D7 to D12 vertebral level for a length of $12.7 \mathrm{~cm}$. The lesion is hyperintense on T1 spin-echo and T2 cube sequences (Figure 1) with complete suppression of the lesion on the fat-saturated sequence (Figure 2). Few fine incomplete $\mathrm{T} 2$ hypointense septations are seen within the lesion (Figure 3). Mass effect is seen in the form of mild prominence of the central canal above the lesion and obliteration of subarachnoid and epidural spaces. It is also causing mild scalloping of the posterior cortex of the adjacent vertebral bodies (Figure $4)$. The rest of the spinal cord was normal in signal intensity. No adjacent bony abnormalities were seen. No tethering of the spinal cord was seen.

Laminectomy and decompression surgeries were done and the same diagnosed on histology. The patient still has residual weakness in legs postoperatively. 


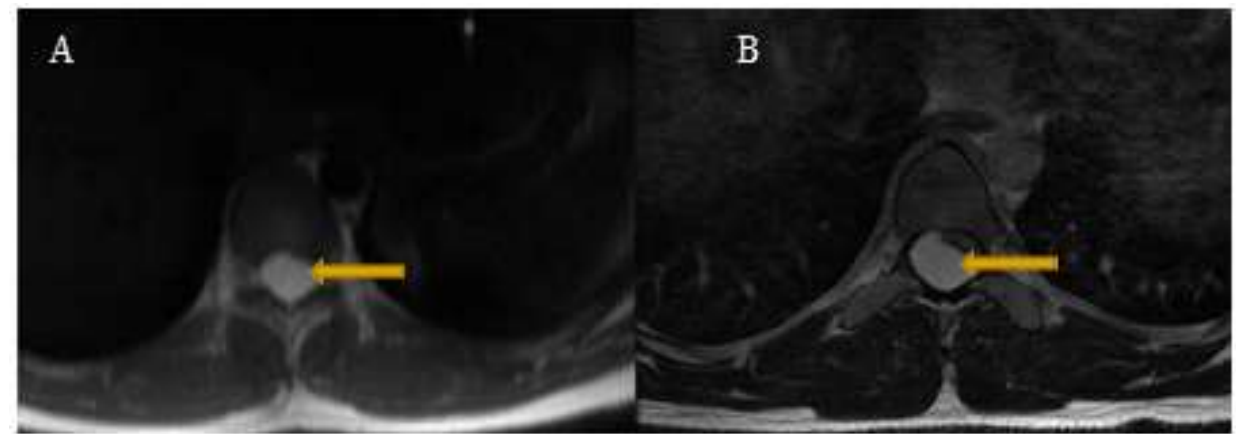

Fig-1: A. Axial T1 spin echo image shows a well-defined hyperintense lesion (arrow) involving the dorsal spinal cord. B. Axial T2w cube image shows the lesion is hyperintense effacing adjacent subarachnoid spaces

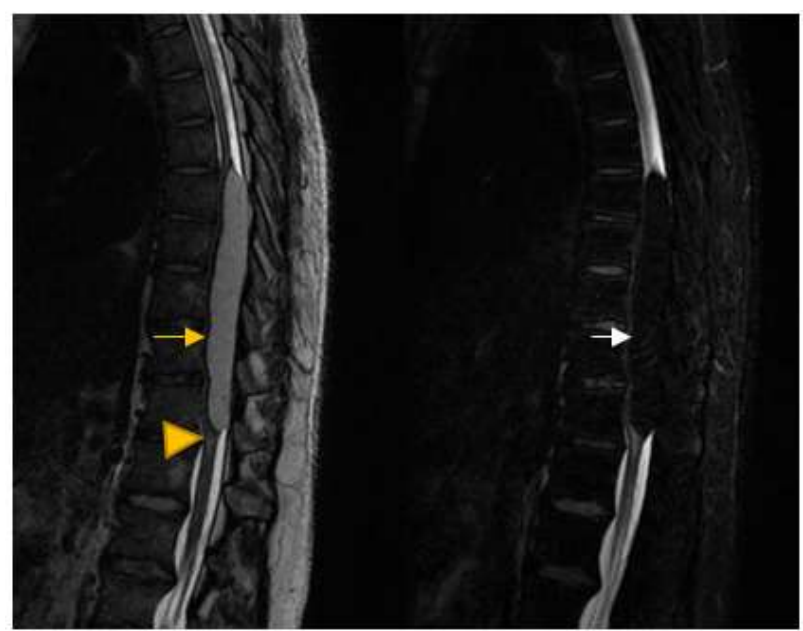

Fig-2: A. Sagittal T2 weighted image shows an oblong T2 hyperintense intramedullary lesion extending over vertebral bodies at the level of D7-D12 (yellow arrow). There is splaying of the medulla inferiorly (arrowhead). B. Sagittal T2 fat-saturated image shows that the lesion (white arrow) is completely suppressed suggesting fat

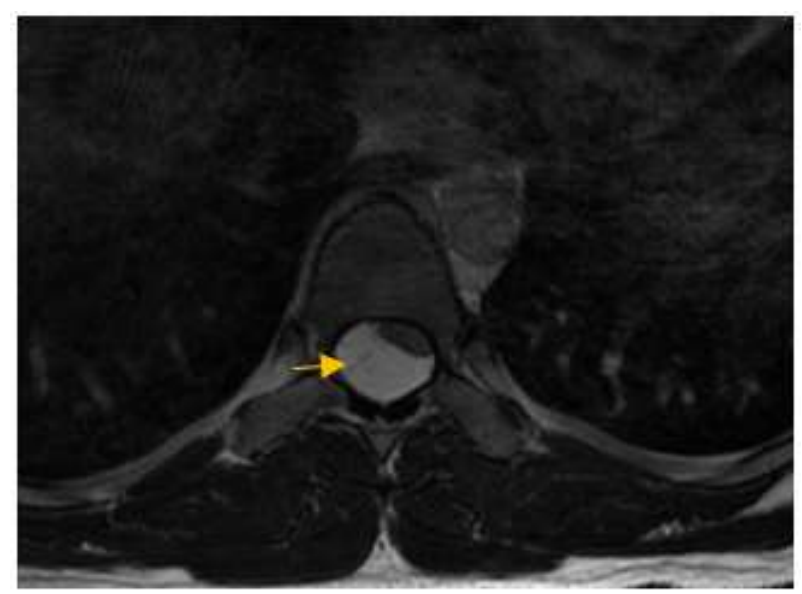

Fig-3: Axial T2w cube image showing fine hypointense septa (arrow)

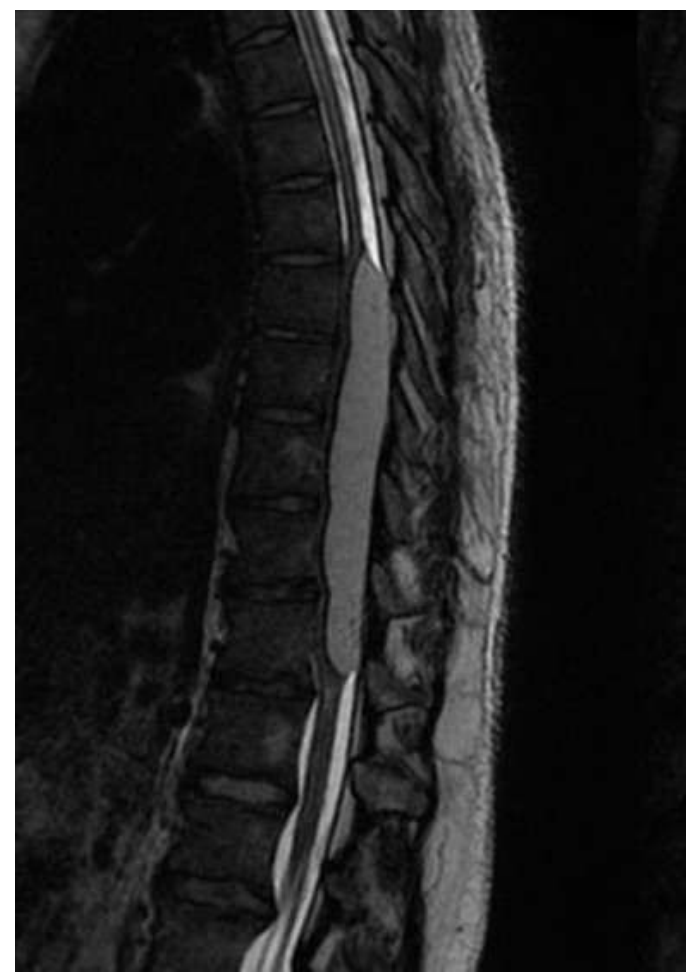

Fig-4: Sagittal T2 weighted image show scalloping of the posterior cortex of vertebral bodies (arrow)

\section{DISCUSSION}

The first reported case of spinal lipoma was that of Gowers in 1876 [3]. In 1945, Ehni and Lore first published the case series of intradural lipoma without spinal dysraphism as a separate entity [4]. Spinal cord lipomas are commonly extradural and seen in the lumbosacral region. Intramedullary spinal cord lipoma is commonly associated with abnormalities of the spine, such as spina bifida, lipomyelomeningocele, myelomeningocle and diastematomyelia [5]. Many postulations are made for its development like adipose cell proliferation, fat deposition and metaplastic differentiation. However, its origin is debatable [6]. The typical clinical presentation is spastic para- or tetraparesis and pain. If the dorsal column of the spinal cord is involved, the patient also presents with numbness. Most of the patients have insidious onset with a progressive course [7]. 
The first investigation to be done is conventional imaging to rule out any bony abnormalities. No abnormality is seen in the majority of cases except for posterior vertebral scalloping and the widening of the spinal canal. The latter is predominantly seen in large tumors of long duration. MRI is the investigation of choice and it can be diagnostic also. Apart from diagnosis, MRI delineates the relationship with adjacent neural and soft tissue. The lesion is typically oblong extending over 4-5 vertebral bodies appearing hyperintense of T1WI. Due to variable relaxation times of fat on T2-weighted images, it can appear hyperintense, isointense or hypointense [8,9]. Suppression on fat-saturated sequences is diagnostic of the tumor. Associated abnormalities like tethered cord have to be ruled out. If MRI is contraindicated, computed tomography can be done to delineate the lesion. On computed tomography, the lesions characteristic fat attenuation within. But it is considered inferior to MRI in characterising the lesions as it can't well demonstrate the adjacent neural tissue [10].

No consensus is reached regarding the treatment strategy. Some authors believe that there is no requirement of treatment in asymptomatic patients and surgery is done only in patients with neurological disabilities [11]. Surgery aims to decompress the adjacent neural structures from the pressure. Despite its benign features, surgical removal is not possible due to the adhesions to surrounding neural tissues. Attempt to remove leads to neural injury and may cause impaired neurological functions [12]. The patients who present with severe neurological dysfunction have a very poor prognosis and show less improvement after surgery [13].

\section{Conclusion}

Intramedullary spinal cord lipomas with spinal dysraphism are rare. These tumors are benign with a progressive course. The common presentation is gradual onset paraparesis with progressive course. MRI is the investigation of choice with the lesion appearing hyperintense on T1WI and classic suppression of the lesion on the fat-saturated sequences. Treatment usually requires debulking to preserve some neurological functions.

\section{REFERENCES}

1. Basavaraj A, Kadam M, Chugh A, Kadam DB. Spinal intramedullary lipoma without dysraphism. J Assoc Physicians India. 2014;62(OCT 2014):42.

2. Solomou A, Panagiotopoulos V, Kraniotis P, Apostolopoulou K, Tzortzidis F. Massive bilocular spinal cord intramedullary lipoma of the thoracic spine. BJR case reports. 2017;3(4):20170009.

3. Caram PC, Carton CA, Scarcella G. Intradural lipomas of the spinal cord; with particular emphasis on the intramedullary lipomas. J Neurosurg. 1957;14(1):28-42.

4. Ehne G, LoveJG. Intraspinal lipomas. Arch neural psychiatry. 1945;53:1-28.

5. Severino R, Severino P. Cervical intramedullary spinal cord lipoma. Surg Neurol Int. 2017 Oct 24;8:255.

6. Corr P, Beningfield SJ. Magnetic resonance imaging of an intradural spinal lipomas. Clin radiology 1989;40:216-8.

7. Bekar A, Şahin S, Taşkapiloğlu Ö, Aksoy K, Tolunay Ş. Intradural spinal lipoma: Report of a thoracic case and a lumbar case. Turk Neurosurg. 2004;14(1-2):52-6.

8. Aoki N: Rapid growth of intraspinal lipoma demonstrated by magnetic resonance imaging. Surg Neurol. 34:107-110, 1990.

9. Kodama T, Numaguchi Y, Gellad FE, Sadato N: Magnetic resonance imaging of a high cervical intradural lipoma. Comp Med Imaging Graph. 15:93-5, 1991.

10. Dooms GC, Hricak H, Sollitto RA, Higgins CB. Lipomatous tumors and tumors with fatty component: MR imaging potential and comparison of MR and CT results Radiology. 1985;157(2):479-83.

11. Dyck P. Intramedullary lipoma. Diagnosis and treatment. Spine. 1992; 17: 979-81.

12. Arslan E, Kuzeyli K, Acar Arslan E. Intraspinal lipomas without associated spinal dysraphism. Iran Red Crescent Med J. 2014 May;16(5):e11423.

13. Lee M, Rezai AR, Abbott R, Coelho DH, Epstein FJ. Intramedullary spinal cord lipomas. J Neurosurg. 1995; 82: 394-400. 